\title{
Editorial
}

\section{Nature, Biological Action and Standardization of Ultra-high Dilutions}

\section{Saurav Arora}

Homeopathy has been debated majorly on three aspects - nature, biological action and standardization of high dilutions. Despite advances in basic, fundamental, clinical and standardization research, the preparation, notification and registration of homeopathic medicines is still debatable in many countries. This issue of International Journal of High Dilution Research features articles on these important aspects of high dilutions.

With the discovery of nanoparticles (NPs) biomedical science is shrinking to nanomedicne. The role of NPs as therapeutic agents on cellular, molecular and dynamic levels is now an area of exploration. ${ }^{1,2}$ Research is being undertaken to develop targeted therapies with NPs.3,4 In homeopathy too, the presence of NPs in ultra-high dilutions (UHDs) has opened new frontiers. There is a fierce debate whether therapeutic action of UHDs are because of NPs, and if yes how homeopathy differs from nanomedicine. The issue is sensitive, challenging and controversial. It can only be overcome by extensive research before concluding homeopathy as Nanoscience.

A work by E S Rajendran contributes to this long debated issue. Using HRTEM and EDS techniques, the experiments conducted by him suggest that UHDs (even far beyond Avogadro) of Iron contain NPs, whose size is within range of quantum dots. Rajendran proposes that the NPs exists randomly in a solution and not only on surface alone, as observed by Chikramane et al previously. ${ }^{5}$

The next article by Aleixo and team studied the association of ponderal Benznidazole and its UHD in mice infected with Trypanosoma cruzi. Authors conclude that it is possible to reduce the side effects of a toxic drug as well as its dose may be adjusted to higher concentration, if the UHD of same drug is given along as add-on. This preliminary work is expected to contribute a new understanding to cases where high doses of toxic drugs are used, and adherence to the therapy is hampered due to side effects and immune suppression. Few similar studies ${ }^{6,7}$ with homeopathy as add-on therapies have been reported so far, with promising results but using the UHDs of same drug is a matter of further exploration.

The third article presents results of an important survey. Robelma Marques and team describes the characterization of potentized medicines notified and registered in Brazil. The results of the study depict status of homeopathic medicines as industry in Brazil. This may be a useful reference material for ANVISA and global industry sector to improve its regulatory activities.

The exploration has just begun and the road ahead is tough!

\section{References}

1. Treuel L, Jiang X, Nienhaus GU. New views on cellular uptake and trafficking of manufactured nanoparticles. Journal of the Royal Society Interface. 2013;10(82):20120939.

2. Bogart LK, Pourroy G, Murphy CJ, et al. Nanoparticles for Imaging, Sensing, and Therapeutic Intervention. ACS Nano. 2014;8(4):3107-3122.

3. Sharma R, Kaur A, Sharma AK, Dilbaghi N, Sharma AK. Nano-based Anti-tubercular Drug Delivery and Therapeutic Interventions in 
Tuberculosis. Curr Drug Targets.

2015 Aug 4.

4. Margulis K, Neofytou EA, Beygui RE, Zare RN. Celecoxib Nanoparticles for Therapeutic Angiogenesis. ACS Nano. 2015 Sep 22;9(9):9416-26.

5. Chikramane PS, Suresh AK, Bellare IR et al. Extreme homeopathic dilutions retain starting materials: a nanoparticulate perspective. Homeopathy 2010; 99: 231-242

6. Chand KS, Manchanda RK, Mittal R, Batra S, Banavaliker JN, De I.
Homeopathic treatment in addition to standard care in multi-drug resistant pulmonary tuberculosis: a randomized, double blind, placebo controlled clinical trial. Homeopathy 2014;103(2):97-107

7. Mourao LC, Moutinho H, Canabarro A. Additional benefits of homeopathy in the treatment of chronic periodontitis: a randomized clinical trial. Complement Ther Clin Pract. 2013 Nov;19(4):246-50

(C) International Journal of High Dilution Research.

Not for commercial purposes.

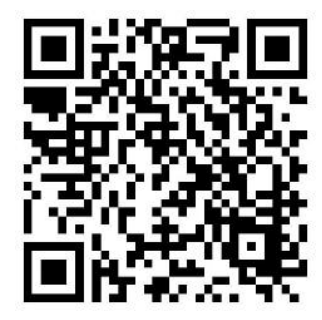

